\title{
Health care costs associated with acute asthma: A prospective economic analysis
}

\author{
Naser Awadh Behbehani MB FRCPC ${ }^{1}$, Anton Grunfeld MD FRCPC ${ }^{2}$, \\ J Mark FitzGerald MB DM FRCP FRCPC ${ }^{1}$ \\ ${ }^{1}$ Department of Medicine, Respiratory Division and ${ }^{2}$ Department of Surgery, \\ Division of Emergency Medicine, Vancouver Hospital and Health Sciences Centre, \\ University of British Columbia, Vancouver, British Columbia
}

\begin{abstract}
NA Behbehani, A Grunfeld, JM FitzGerald. Healthcare costs associated with acute asthma: A prospective economic analysis. Can Respir J 1999;6(6):521-525.
\end{abstract}

OBJECTIVE: To determine the direct and indirect costs associated with the care of acute asthma in an adult teaching hospital.

DESIGN: A prospective, cost identification study.

PATIENTS AND METHODS: Patients aged 15 to 55 years presenting with acute asthma. Consecutive emergency department visits for asthma at Vancouver Hospital and Health Sciences Centre over six months were prospectively monitored. The duration of hospital stay, physician's care, laboratory procedures and medication given were recorded. Time lost from work or school was determined by follow-up telephone calls. The costs were calculated in 1997 Canadian dollars.

RESULTS: One hundred and forty-nine patients made 195 emergency department visits over the six-month study. Twentyeight (14\%) of these visits led to hospital admissions. The total cost associated with the care of these patients was $\$ 250,570$. The median (standard deviation in brackets) direct medical costs associated with each emergency department visit and hospital day were $\$ 324.00( \pm 52.00)$ per visit, and $\$ 677.00( \pm 76.00)$ per day, respectively.

CONCLUSION: The present study provides a more accurate estimation of the operational cost of managing asthma in a teaching hospital setting than previous studies. The data presented in this study can be used in future cost effectiveness and cost-benefit studies in acute asthma, particularly where these studies involve specific intervention such as asthma education. More studies, which include children with asthma and patients treated outside of the hospital setting, are needed.

Key Words: Acute asthma; Economic evaluation

Le coût des soins de santé requis par la crise d'asthme : Analyse économique prospective

OBJECTIF : Déterminer les coûts directs et indirects associés au traitement des crises d'asthme aiguës dans un hôpital universitaire pour adultes.

MODÈLE : Étude prospective de calcul des coûts.

PATIENTS ET MÉTHODES : Patients âgés de 15 à 55 ans se présentant pour une crise d'asthme aiguë. Les visites consécutives effectuées au service des urgences pour asthme au Vancouver Hospital and Health Sciences Centre sur une période de six mois ont été étudiées de façon prospective. La durée du séjour hospitalier, les soins médicaux, les épreuves de laboratoire et les médicaments administrés, ont tous été consignés. L'absentéisme au travail ou à l'école a été déter-

voir page suivante 
miné au moyen d'un suivi téléphonique. Les coûts ont été calculés en dollars canadiens de 1997.

RÉSULTATS : Cent quarante-neuf patients ont totalisé 195 visites au service des urgences au cours des six mois de l'étude. Vingt-huit (14\%) de ces visites ont abouti à une hospitalisation. Le coût total associé aux soins prodigués à ces patients a été de 250570 \$. Les coûts médicaux directs médians (écart-type entre parenthèses) associés à chaque consultation au service des urgences et à chaque jour d'hospitalisation s'élevaient respectivement à 324,00 \$ $( \pm 52,00 \$)$ par visite $)$ et à $677,00 \$( \pm 76,00 \$)$ par jour.
CONCLUSION : La présente étude offre une estimation plus précise des coûts opérationnels du traitement de l'asthme dans un hôpital universitaire comparativement aux études précédentes. Les données présentées dans cette étude pourront être utilisées dans le cadre d'études coût-efficacité et coût-bénéfices futures appliquées à l'asthme aigu, particulièrement pour évaluer certaines interventions spécifiques, comme l'enseignement aux asthmatiques. Il serait souhaitable de procéder à d'autres études qui incluraient une population pédiatrique asthmatique et des patients traités à l'extérieur du contexte hospitalier.
$\mathrm{D}$ espite substantial progress in understanding the pathophysiology of acute asthma and in the development of new drugs for its treatment, there is a concern regarding the increasing morbidity (1) and mortality (2) from this disease. A recent Canadian study has shown that although rates of asthma deaths are levelling off, there has been a significant increase in rates of hospitalization for asthma throughout the 1980s (3). This trend is disconcerting not only because of the impact of asthma on the quality of life of patients, but also because of the enormous costs associated with the management of this disease. Expenditures for hospitalization and emergency department visits constitute a substantial portion of the total costs associated with asthma care. In addition, both visits and hospitalization have been used as outcome measurements of different intervention programs. In this study, we therefore focused on the costs associated with hospital care of patients with acute asthma.

There is increasing interest in the evaluation of the cost of different health services in clinical practice. Economic evaluation studies can be divided into three types: cost identification; cost effectiveness and cost-benefit (4). The total cost of an illness is divided into direct costs (both fixed and variable), indirect costs and intangible costs (4). Intangible costs, such as the pain and suffering associated with an illness, are rarely directly accounted for in an economic evaluation because of the difficulty in measuring and valuating them. Indirect costs, such as time lost from work due to the illness, are included more often, with their value usually assigned by a human capital approach. Our study is a cost identification study examining the direct costs associated with the management of asthma in hospital as well as the indirect costs (time lost from work or school) incurred by the patient. The importance of accurately measuring these health care costs related to asthma is increasing with the recognition of the pivotal role that patient education plays in asthma management $(5,6)$ and its potential for reducing the utilization of scarce health care resources. Accurate measurement of health care costs related to asthma may facilitate appropriate cost effectiveness analyses of asthma intervention programs such as asthma education. Our primary aim was to estimate costs for our own institution.

\section{PATIENTS AND METHODS}

Vancouver Hospital and Health Sciences Centre (VHHSC), formerly Vancouver General Hospital, is a uni- versity affiliated teaching hospital for adult patients. It is the major referral centre for the province of British Columbia. It also serves as a community hospital for the city of Vancouver.

For six months from October 1992 to March 1993, all patients between the ages of 15 and 55 years who presented to the VHHSC emergency department with acute asthma were invited to participate in the study. Research nurses obtained informed consent for a follow-up evaluation by a telephone questionnaire. The patients who presented to the emergency department when the research staff were not on duty were contacted by a letter, and the data on health care utilization were abstracted from their medical records.

The diagnosis of asthma was based on standard American Thoracic Society criteria (7). We chose 55 years as the upper limit for age to avoid possible contamination by chronic obstructive pulmonary disease patients. Demographic data, asthma history, investigations and treatment carried out in the emergency department were recorded. Patients admitted to the hospital were followed until discharge. Investigations and treatment carried out in the hospital were recorded. All patients who consented to the follow-up evaluation were contacted by phone to determine the amount of time lost from work or school related to their recent acute attack of asthma. The first phone call was made within a week of discharge, and if necessary, subsequent calls were made weekly until the patient returned to work or recovered completely from the acute attack.

Cost calculation: Hospital costs consisting of nonphysician labour, supply and overhead costs were based on VHHSC costs for the fiscal 1991 year (VHHSC finance department, personal communication) using a fully allocated costing methodology. These costs are $\$ 186.56 /$ emergency department visit, \$410.52/hospital day for medical units, and $\$ 1581.77 /$ hospital day for the intensive care unit (ICU). These figures were adjusted for 1997 dollars using the inflation rates in Canada between 1991 to 1997. The costs for the nursing units consist only of labour, supplies and overhead costs directly related to that unit. Costs for medications and investigative procedures are not included in these figures.

Other direct costs that were calculated included physician fees, and medication, laboratory and ambulance service costs. Physician costs were based on British Columbia's medical service plan fees schedule. These fees for 1997 were as follows: emergency department physician consultation at $\$ 48.30$, specialist consultation at $\$ 121.19$; and 


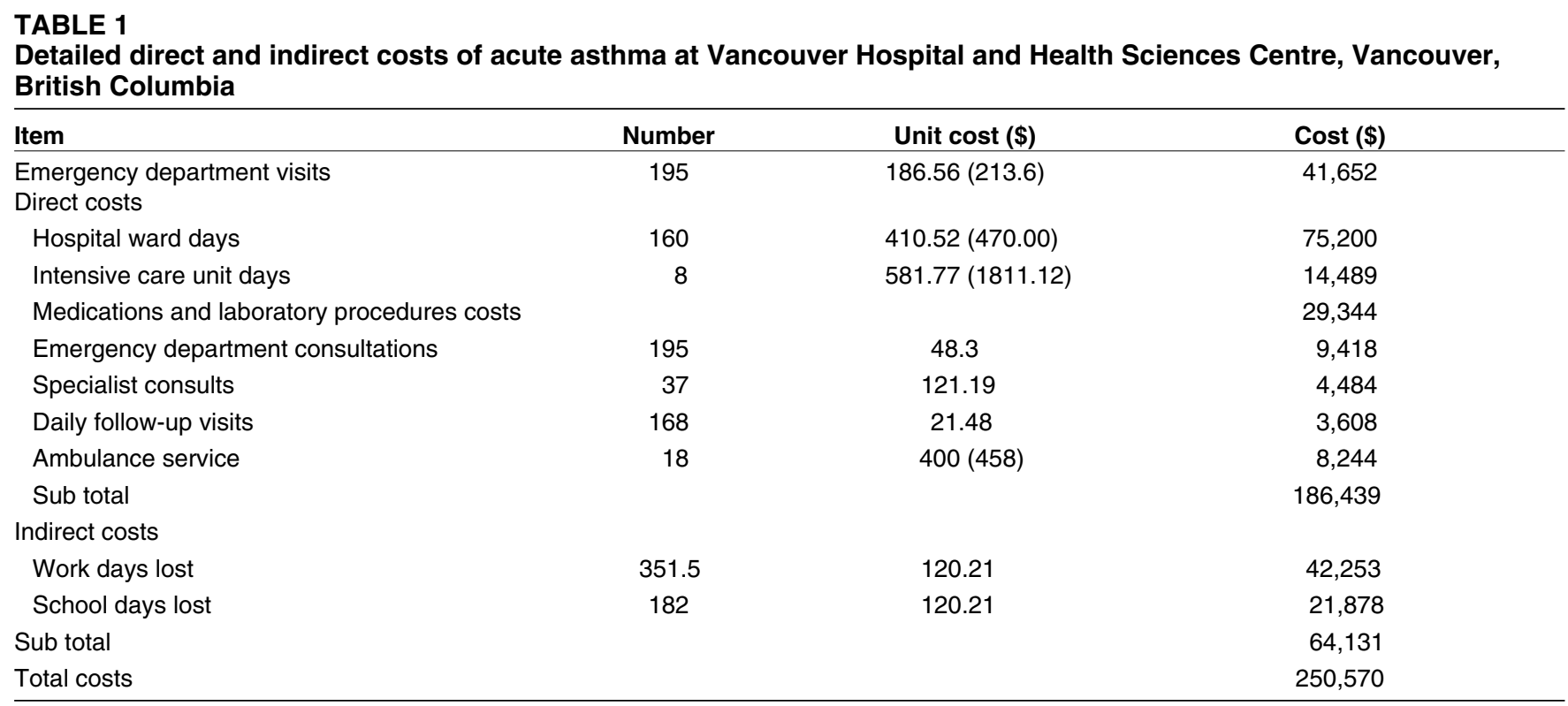

The numbers in parentheses are unit costs adjusted for 1997 using inflation rates in Canada between the years 1991 to 1997 (14\% for the whole period).

follow-up visit on the ward while the patient is in hospital at $\$ 21.48 /$ visit. The laboratory procedures costs for 1997 were based on VHHSC's fully allocated costing methodology (8). Medication costs were based on VHHSC pharmacy acquisition costs for 1997 and costs of preparing the drugs.

An indirect cost of $\$ 601.06 /$ week for time lost to work or school was based on the average weekly earnings of industrial workers in Canada (9). Because all patients were adults (18 years of age and older), days lost from school were considered equivalent to days lost from work in terms of costs.

\section{RESULTS}

One hundred fifty-seven patients made 203 consecutive emergency department visits for acute asthma during the six months. Eight visits were for the renewal of prescriptions and were not included in the study. The remaining 149 patients were included in this study and they made 195 emergency department visits. The maximum number of emergency department visits made by any one patient was four. All patients except one were either self-referred or referred by their general practitioner to the emergency department. Twenty-eight visits (14\%) led to hospital admissions. The mean duration of hospitalization was 5.9 (range two to 23) days. Two patients were admitted to the ICU, one for two days and the other for six days. The mean age of the patients was $32 \pm 10$ years, and 100 patients $(67 \%)$ were women. The mean peak expiratory flow rate and forced expiratory volume in the $1 \mathrm{~s}$ at presentation were $232 \pm 95 \mathrm{~L} / \mathrm{min}$ and $1.5 \pm 0.65 \mathrm{~L} / \mathrm{min}$, respectively. Followup information on time lost from work or school was available for 129 patients $(87 \%)$. Forty-seven patients $(32 \%)$ were unemployed. Twenty-seven (18\%) did not lose any time from work or school because of their attack. The total number of days lost from work and school was 351.5 days and 182 days, respectively. The total cost of care for the 149 patients during the study period was $\$ 250,570$ (Table 1). The majority of these costs $(\$ 186,439$ or $74 \%)$ were for direct care. The median direct medical costs (SD) associated with each emergency department visit and hospital day were $\$ 324.00( \pm 52.00)$ and $\$ 677.00( \pm 76.00)$, respectively. The costs associated with a hospital day were calculated for patients admitted to general wards only and excluded the two patients admitted to the ICU.

\section{DISCUSSION}

Our study showed that the costs associated with the care of acute asthma in the hospital setting are substantial. It is the first study that prospectively looked at direct medical costs associated specifically with the care of bronchial asthma patients in an adult teaching hospital in Canada.

There are several reports on the economic burden of asthma in different countries (10-14). In the United States, the cost of illness related to asthma in 1990 was estimated to be US $\$ 6.2$ billion. Thirty per cent of the costs, US $\$ 1.85$ billion, were related to hospital care (inpatient and emergency department). This analysis had some limitations because the costs per emergency department visit and hospitalization were based on estimates derived from global hospital expenditures rather than actual measurements specific for asthma. In a report by the Boston Consulting Group commissioned by Glaxo Canada (now Glaxo Welcome Inc) (11), the institutional care (inpatient, emergency department and nursing home) costs related to adult asthma in Canada were estimated to be $\$ 145$ million. This represented 24\% of the total cost of care 
for adult asthma patients and $37 \%$ of the direct medical cost. In this report, the unit costs per emergency department visit and inpatient hospital day were $\$ 118$ and $\$ 447$, respectively. These figures were based on information from Statistics Canada for inpatient hospital day cost, and information from Peel Memorial Hospital and Hamilton Health Sciences Corporation for emergency department visits.

The present study is an attempt to look at the medical costs associated with bronchial asthma in the hospital setting. It provides an opportunity to determine both direct and indirect costs, specifically for asthma. The study, however, still underestimates the true total societal cost of acute asthma care in hospital. We did not account for capital expenditure in terms of buildings and equipment. The value of time lost from house keeping and intangible costs were not measured. Many of our patients were unemployed. Our study, however, was not set up to measure or verify the longterm disability due to asthma among these patients. We focused on the costs related to an acute attack of asthma rather than the costs of the long term disability. Further, we did not account for costs associated with death from asthma, a relatively rare event that usually occurs in the community. We valued the time lost from school the same as the time lost from work because we believe that, in this adult population, both lead to the equivalent loss of production.

Our study was conducted at a teaching hospital in an urban setting and this limits our ability to project our results to hospitals across Canada. VHHSC is a general adult teaching hospital, hence our total figures may not apply to smaller community hospitals. In Canada, the total operating expenses per in-hospital patient day for the fiscal year 1990 to 1991 were $\$ 518.17$ for all hospitals, $\$ 681.70$ for teaching hospitals (excluding pediatrics hospitals) and $\$ 496.81$ for nonteaching hospitals with no long term care facilities (15). These figures include emergency department expenditures but excluded physicians' fees. The figure for nonteaching hospitals is $73 \%$ of the cost for teaching hospitals. We believe that the figures we obtained for direct medical care related to bronchial asthma, $\$ 677.00$ $( \pm 76.00) /$ patient hospital day and $\$ 324.00( \pm 52.00) /$ emergency department visit, may be used for teaching hospitals across Canada. For nonteaching hospitals, the figures $\$ 506$ and $\$ 243$ can be used, representing $75 \%$ of the costs that we obtained for teaching hospitals.

It was more difficult to determine a representative mean of the value of time lost to work or school related to an acute attack of asthma. This was partly because of the high percentage of unemployed people among our patients, and partly because of the wide range in the number of days lost to work or school. To overcome this, we recalculated the average time lost from work or school, after allowing a maximum of seven days after discharge from hospital or emergency department as time lost from work or school. By doing this, the mean number of days lost from work or school was 1.95 days $( \pm 2.5)$ after an emergency department visit and 8.1 days $( \pm 6.9) /$ hospitalization. The mean dollar value of time lost from work or school was $\$ 234.00( \pm 300.00)$ after an emergency department visit and \$974.00 ( \pm 829.00$)$ after hospitalization. With a seasonal disease such as asthma, a six-month study may not reflect the true incidence of emergency department visits or hospitalization for asthma in the study population. However, the number of emergency department visits for the six months immediately following the study period was only slightly different, at 244 visits with the same percentage of hospitalization. Furthermore, the duration of the study should not affect the costs associated with the management of an acute attack of asthma, on which we focused.

Several cost effectiveness studies looking at the effect of patient education programs on asthma control and health care utilization have been published (16). In a controlled, randomized study, Clark and colleagues (17) showed that an asthma education program for children with one or more hospitalizations resulted in savings of $\$ 11.22$ in health care costs for every dollar spent to deliver the education program. Mayo and colleagues (18) showed that in a population of adult asthmatic patients who frequently visited the emergency department and had multiple hospital admissions, an education program resulted in a threefold reduction in admission rates and a twofold reduction in days spent in hospital. Yoon and colleagues (19) showed that a 3 $\mathrm{h}$ education session for adult patients after hospitalization for asthma resulted in a sevenfold decrease in admission rate over 10 months compared with a control group. This reduction was attributed to a change in behaviour and selfmanagement plans rather than an improvement in asthma severity. There are several other studies that show that selfmanagement plans and asthma education improve asthma symptoms and rates of acute exacerbation (20-23). Interpretation of the cost effectiveness of these interventions has been limited by the absence of prospectively collected data on health care costs related to asthma. Such an assessment is particularly important in delivering asthma education to high risk population groups (24).

Although this study is the first prospective study of health care costs associated with acute asthma, it carries with it the limitations of being from a single institution. Our results may apply for other teaching hospitals across Canada, but not to smaller community hospitals. Future studies should be undertaken in different health care settings in an effort to confirm similar findings. Pertinent issues might involve assessing costs in a wider range of patient and ethnic groups. Health care studies in the area of asthma should extend our observations by addressing the issues of quality of life in acute asthma as well as the dollar cost. Such evaluations should form an integral part in the development and implementation of evidence-based asthma guidelines $(25,26)$.

ACKNOWLEDGEMENTS: We are grateful to Hans Krueger, from the VHHSC Corporate Planning and finance department, for providing us with the costs associated with services at VHHSC and reviewing the manuscript. We also thank Dr Aslam Anis for reviewing the manuscript, and Linda Hui, Patricia Patrick and Neil Hodgins for their help in data collection. 


\section{REFERENCES}

1. Mao Y, Semenciw R, Morrison H, MacWilliam L, Davies J, Wigle D. Increased rates of illness and death from asthma in Canada. CMAJ 1987; 137:620-4.

2. Jackson R, Sears MR, Beaglehole R, Rea HH. International trends in asthma mortality:1970 to 1985 . Chest 1988;94:914-8.

3. Wilkins K, Mao Y. Trends in rates of admission to hospital and death from asthma among children and young adults in Canada during the 1980's. CMAJ 1993;148:185-90.

4. Eisenberg JM. Clinical economics. A guide to the economic analysis of clinical practice. JAMA 1989;262:2879-6.

5. FitzGerald JM, Swan D, Turner MO. The role of asthma education. CMAJ 1992;147:855-6.

6. Bone RC. The bottom line in asthma management is patient education. Am J Med 1993;94:561-3.

7. American Thoracic Society. Standards for the diagnosis and care of patients with chronic obstructive pulmonary disease (COPD) and asthma. Am Rev Respir Dis 1987;136:225-43.

8. Guidelines for Management Information Systems in Canadian Health Care Facilities (MIS Guidelines). Ottawa: Canadian Institute for Health Information.

9. Statistics Canada. Employment earning and hours [catalogue 72-002]. Ottawa: Government of Canada, 1991.

10. Weiss KB, Gergen PJ, Hodgson TA. An economic evaluation of asthma in the United States. N Engl J Med 1992;326:862-6.

11. Boston Consulting Group, Glaxo Canada Inc. The costs of adult asthma in Canada. Boston: Boston Consulting Group, 1993.

12. Mellis CM, Peat JK, Bauman AE, Woolcock AJ. The cost of asthma in New South Wales. Med J Aust 1991;155:522-8.

13. Krahn MD, Berka C, Langlois P, Detsky AS. Direct and indirect costs of asthma in Canada, 1990. CMAJ 1996;154:821-31.

14. Smith DH, Malone DC, Lawson KA, Okamoto LJ, Battista C, Saunders WB. A national estimate of the economic costs of asthma. Am J Respir Crit Care Med 1997;156:787-93.
15. Hospital Statistics: preliminary Annual Report, catalogue 83-241;1990-1991. Ottawa: Statistics Canada, 1992.

16. Molken MP, Van Doorslaer EK, Rutten FF. Economic appraisal of asthma and COPD care: a literature review 1980-1991. Soc Sci Med 1999;35:165-71.

17. Clark NM, Feldman CH, Evans D, Levison MJ, Wasilewski Y, Mellins RB. The impact of health education on frequency and cost of health care use by low income children with asthma. J Allergy Clin Immunol 1986;78:108-15.

18. Mayo PH, Richman J, Harris HW. Results of a program to reduce admissions for adult asthma. Ann Intern Med 1990;112:864-71.

19. Yoon R, McKenzie DK, Bauman A, Miles DA. Controlled trial evaluation of an asthma education program for adults. Thorax 1993;48:1110-6.

20. Charlton I, Charlton G, Broomfield J, et al. Evaluation of peak flow and symptoms only self management plans for control of asthma in general practice. BMJ 1990;301:1355-9.

21. Beasley R, Cushley M, Holgate ST. A self management plan in the treatment of adult asthma. Thorax 1989;44:200-4

22. Turner MO, Taylor D, Bennett R, FitzGerald JM. A randomized trial comparing peak expiratory flow and symptom self-management plans for patients with asthma attending a primary care clinic. Am J Respir Crit Care Med 1998;157:540-6.

23. Boulet L-P, Chapman KR, Green LW, FitzGerald JM. Asthma education. Chest 1994;106(Suppl 4):184S-196S.

24. FitzGerald JM, Turner MO. Delivering asthma education to high risk groups. Patient Educ Couns 1997;32(Suppl 1):S77-S86.

25. Ernst P, FitzGerald JM, Spiers S. Canadian Asthma Consensus Conference: Summary of recommendations. Can Respir J 1996;3:89-100.

26. FitzGerald JM, Ernst P, Spiers S. Evidence-based asthma guidelines. Chest 1996;110:1382-3. (Edit) 


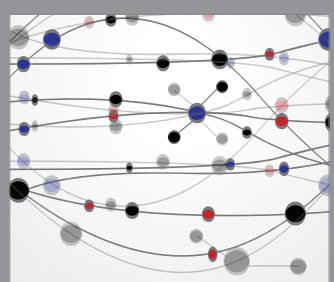

The Scientific World Journal
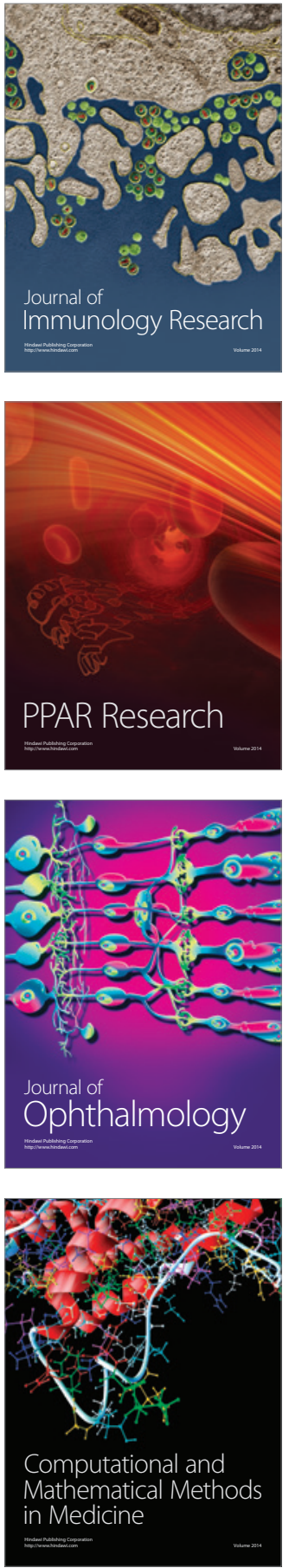

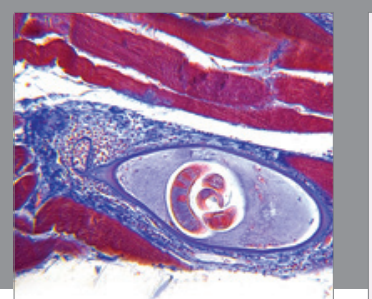

Gastroenterology Research and Practice

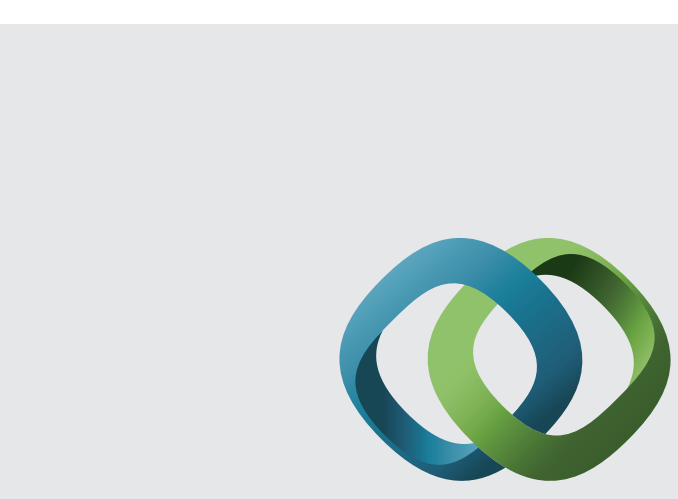

\section{Hindawi}

Submit your manuscripts at

http://www.hindawi.com
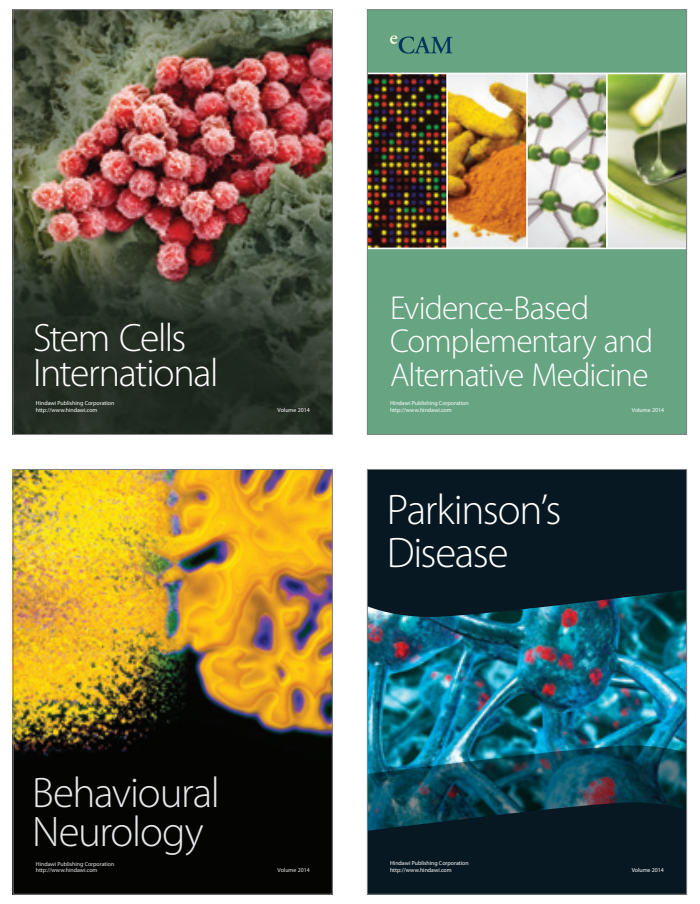
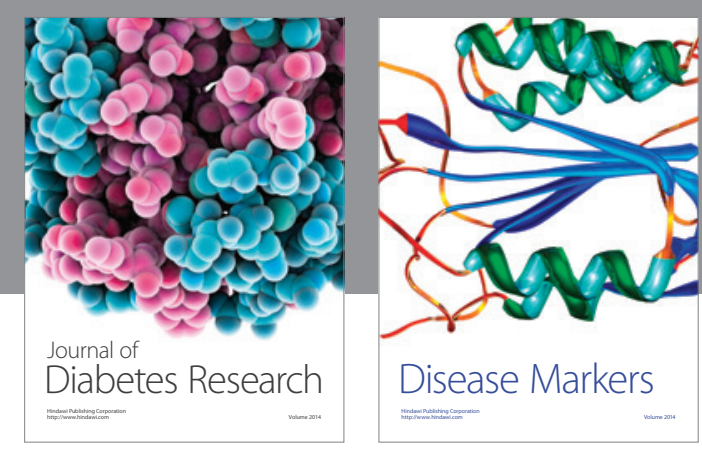

Disease Markers
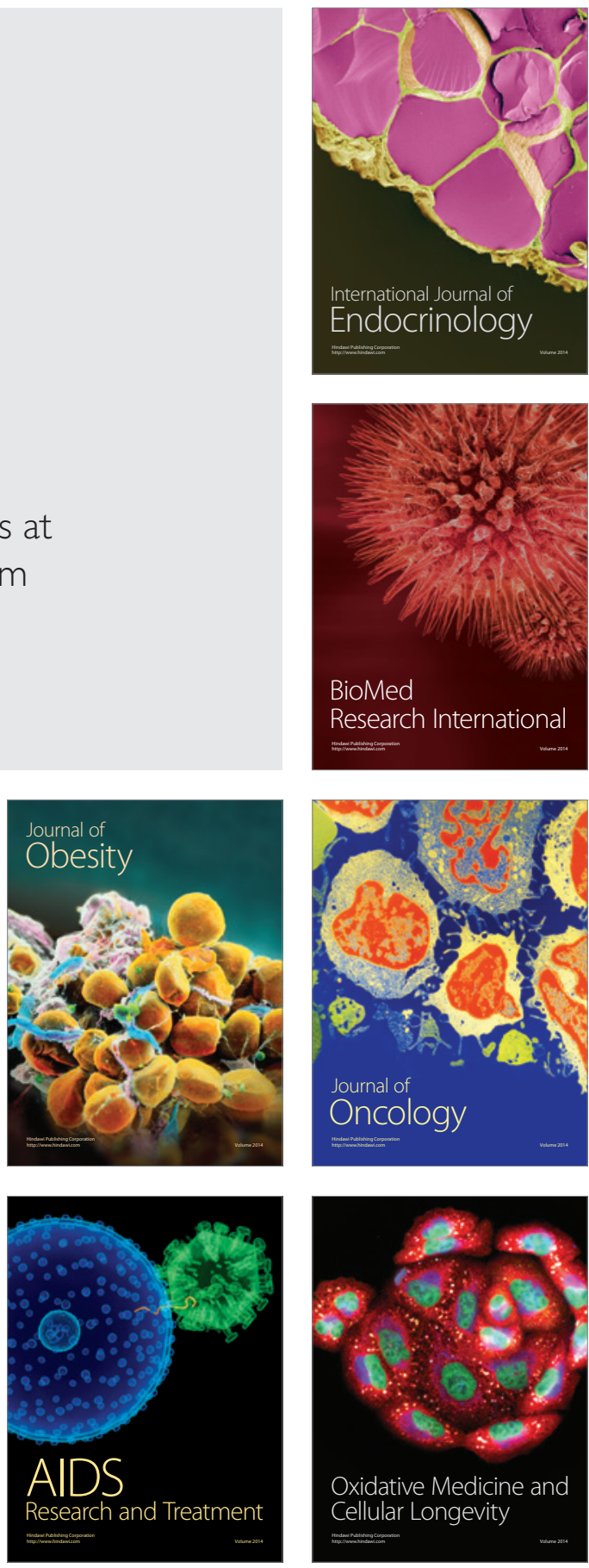